\title{
Body Mass Index in Systemic Lupus Erythematosus: Relation to Disease Activity, Bone Mineral Density And Vitamin D Level \\ Dalia A. El-Sherbiny ${ }^{1}$, Mohja A. El-Badawy ${ }^{* 2}$, Amira R. Elmahdi ${ }^{3}$
}

${ }^{1}$ Department of Internal Medicine, Rheumatology, ${ }^{2}$ Department of Physical Medicine, Rheumatology, and Rehabilitation, ${ }^{3}$ Department of Internal Medicine, Allergy and Clinical Immunology, Faculty of Medicine, Ain Shams University, Cairo, Egypt

*Corresponding author: Mohja Ahmed Elbadawy, Mobile: 00201005048716 -002 01111434418 ,

E-mail: mohjaelbadawy@gmail.com

\begin{abstract}
Background: High incidence of obesity has been reported in Systemic Lupus Erythematosus (SLE). However, the relationship between obesity and SLE is still unclear. Studies reported low vitamin D levels and bone mineral density (BMD) in SLE patients. Moreover, vitamin D plays a vital role in the pathogenesis and complication of SLE.

Objective: To investigate the link between increased body mass index (BMI), disease activity, BMD, and vitamin D level in SLE patients .

Patients and Methods:120 SLE patients were classified according to BMI into three groups, normal BMI $(<25$ $\left.\mathrm{kg} / \mathrm{m}^{2}\right)$, overweight $\left(25-29.9 \mathrm{~kg} / \mathrm{m}^{2}\right)$, and obese $\left(>30 \mathrm{~kg} / \mathrm{m}^{2}\right)$. Laboratory investigations were done, assessment of disease activity by the Systemic Lupus Erythematosus Disease Activity Index (SLEDAI), measuring the serum levels of 25-hydroxyvitamin D 25(OH) D were assessed.

Results: $30 \%$ were overweight, and $45 \%$ were obese. Overweight and Obese patients had lower 25(OH) D levels and a high prevalence of osteoporosis in comparison to patients with normal BMI. SLEDAI score was positively correlated to BMI and negatively correlated with $25(\mathrm{OH}) \mathrm{D}$ and BMD.

Conclusion: Increased BMI is common in SLE and is independently associated with higher disease activity, osteoporotic rates, and lower $25(\mathrm{OH})$ vitamin D levels. These findings are associated with important clinical implications, which suggests that weight control may be a potential target for improving SLE outcome.
\end{abstract}

Keywords: Bone mineral density, Obesity, Systemic Lupus Erythematosus, Vitamin D.

\section{INTRODUCTION}

Obesity could modify the chronicity and severity of various autoimmune pathologies, through the release of pro-inflammatory cytokines which are incorporated in the onset and progression of diverse autoimmune diseases, like rheumatoid arthritis, psoriatic arthritis, and multiple sclerosis ${ }^{(\mathbf{1})}$. Studies reported a high predominance of obesity in Systemic Lupus Erythematosus (SLE) ranges between 29 and 50 percent ${ }^{(2)}$.

Reports noticed that obese SLE patients have increased gene and protein expression of various proinflammatory cytokines as IL-23 $3^{(3)}$, and TNF- $\alpha$, which linked to total fat mass ${ }^{(4)}$. Obesity is a state of chronic low-grade inflammation, associated with altered immune function and the release of different adipokines such as leptin ${ }^{(5)}$.

Elevated leptin levels were detected in SLE patients and could be the connection between both obesity and SLE (6-7). Obesity aggravates the inflammatory burden of SLE disease, and contributes to increased cardiovascular disease risk ${ }^{(8)}$. Obese SLE patients are presented with higher disease activity, more depressive symptoms, and fatigue in comparison to non-obese SLE patients ${ }^{(\boldsymbol{9})}$.

Vitamin D is recognized as an immune modulator that regulates innate and adaptive immune response in the presence of vitamin D receptor (VDR) on the surface of natural killer cells, antigen-presenting cells, and B- and T-lymphocytes ${ }^{(\mathbf{1 0})}$.

Studies demonstrate low BMD and vitamin D in SLE patients. An inverse association was observed between SLE disease activity and vitamin D serum level. Moreover, low serum vitamin D levels are combined with poor outcomes in SLE patients including fatigue, cardiovascular diseases, cutaneous, and renal involvement ${ }^{(11)}$.

In this study, we aimed to study the association between increased BMI and disease activity, BMD and vitamin D level in a cohort of SLE patients.

\section{PATIENTS AND METHODS}

The present cross-sectional study enrolled 120 adult SLE patients who were divided into three groups according to BMI based on WHO international classification ${ }^{(\mathbf{1 2})}$. Group I included 30 (25\%) SLE patients with normal weight (BMI $<25 \mathrm{~kg} / \mathrm{m}^{2}$ ), Group II included $36(30 \%)$ SLE patients with overweight (BMI: $25-29.9 \mathrm{~kg} / \mathrm{m}^{2}$ ) and Group III included 54 $(45 \%)$ patients with obesity $\left(\mathrm{BMI} \geq 30 \mathrm{~kg} / \mathrm{m}^{2}\right)$. Patients were recruited from the Department of Rheumatology and the Department of Physical Medicine, Rheumatology, and Rehabilitation including the Obesity Unit Clinic from May 2018 to September 2018. 
The diagnosis of SLE was based on the Systemic Lupus International Collaborating Clinics (SLICC) classification criteria for systemic lupus erythematosus (13). SLE disease activity was determined by the Systemic Lupus Erythematosus Disease Activity Index (SLEDAI) ${ }^{(14)}$. Grades of activity classified as follows: No activity (SLEDAI $=0$ ), mild activity $($ SLEDAI $=1$ 5 ), moderate activity (SLEDAI $=6-10$ ), severe activity $($ SLEDAI $=11-19)$, very highly activity (SLEDAI $>20)$ (15). Patients with a history of chronic or inflammatory diseases that affects the absorption of vitamin D, renal stones, calcium metabolism disorder, liver cirrhosis, malignancy, myocardial infarction, and hospitalization because of the complications of SLE during the study and postmenopausal women were excluded. Drug history of all patients was taken as long-term steroid use more than 60 days and immunosuppressive drugs like Azathioprine (AZA) or antimalarial agents as Hydroxychloroquine Mycophenolatemofetil (MFM).

\section{Ethical approval:}

The study was approved by the Ethical Committee of Ain Shams University (IRB number 000017585), and all patients signed informed consent before participation.

\section{Laboratory Analyses:}

Blood samples were collected for a complete blood cell count (CBC), determination of kidney and liver function tests, C-reactive protein (CRP), Westergren erythrocyte sedimentation rate (ESR) and urine samples were obtained for spot urine protein to creatinine ratio $(\mathrm{P} / \mathrm{C})$.

Anti-dsDNA antibodies were also measured using the enzyme-linked immunosorbent assay (ELISA) technique (Quanta Lite, TMds-DNA Kit, INOVA Diagnostic Inc, CA, USA), and were measured in $\mathrm{IU} / \mathrm{mL}$. Anti-dsDNA tests were classified as negative if the level was between $0-200 \mathrm{IU} / \mathrm{mL}$; equivocal if the level was between 201-300 IU/mL; and positive if the level was above $301 \mathrm{IU} / \mathrm{mL}$. Complement components 3 and 4 (C3) and (C4) were measured by nephelometry (Behring Nephelometer II, Dade Behring, Marburg, Germany), and antinuclear antibodies (ANA) were measured by ELISA.

Bone metabolites were assessed including total serum calcium, serum phosphorus, serum alkaline phosphatase, and serum levels of 25-hydroxy vitamin $\mathrm{D}$ and parathyroid hormone (PTH) were quantitatively measured by ELIZA assay in serum.

The level of serum 25-hydroxyvitamin D 25(OH)D was measured using ELISA technique (K2110, immunodiagnostic [Dutch Company], Holland). Vitamin D deficiency was defined as follows:-

(1) Serum level of 25(OH)D level less than $10 \mathrm{ng} / \mathrm{ml}$ : severe vitamin $\mathrm{D}$ deficiency.

(2) Serum level of 25(OH)D level between 10 and $30 \mathrm{ng} / \mathrm{ml}$ : insufficiency in vitamin D.
(3) Serum level of $25(\mathrm{OH}) \mathrm{D}$ level more than $30 \mathrm{ng} / \mathrm{ml}$ : normal range.

Bone mineral density assessment (BMD):

Bone mineral density (BMD) of the lumbar vertebrae and femoral necks were measured with dual-energy Xray absorptiometry, and patients were stratified as normal and abnormal BMD groups (including osteopenia and osteoporosis). This was performed by GE LUNAR DXA apparatus made in Madison, USA. Bone mass was expressed using $\mathrm{T}$ score according to WHO criteria: (1) Osteoporosis was defined as T score less than -2.5 . (2) Osteopenia was defined as T score from -1.5 to $<2.5$. (3) Normal more than $-1.0^{(16)}$.

\section{Statistical analyses}

Data analysis was performed using the software SPSS (Statistical Package for the Social Sciences) version 20. Quantitative variables were described using their means and standard deviations, range, median and interquartile range (IQR). Categorical variables were described using their absolute frequencies and were compared using Chi square test when appropriate. Kolmogorov-Smirnov (distribution-type) and Levene (homogeneity of variances) tests were used to verify assumptions for use in parametric tests. To compare means of more than two groups, one way ANOVA test (used with normally distributed data) was used.

To compare medians of more than two groups, Kruskal Wallis test (used with not normally distributed data) was used. Least significant difference (LSD) was used as a post-hoc test for multiple comparisons among the studied groups when F was significant. Spearman rank correlation coefficients was used to assess strength and direction of a linear relationship between two variables. The level of statistical significance was set at $5 \%(\mathrm{P}<0.05)$. Highly significant difference was present if $\mathrm{p} \leq 0.001$.

\section{RESULTS}

One hundred and twenty patients with SLE (110 women and 10 men) were studied. Their age ranged from 22 to 45 years with a mean age of $34.14( \pm 6.1$ years). The average SLEDAI score ranged from 0 to 14 with a mean of $3.53( \pm 3.6)$. Regarding disease activity, $(20 \%)$ of patients had mild activity, (48.3\%) had moderate activity, while $(26.7 \%)$ had severe activity. The average BMI was $(29.37 \pm 6.46),(30 \%)$ of patients were over-weight, while (45\%) were obese.

Table 1 shows the characteristics of the three studied groups. ESR was higher in the overweight and normal-weight compare to the obese group. Regarding patients' treatment, a significant increase in azathioprine was found in overweight and obese groups compared to the normal weight group. There was a statistically significant relationship between BMI categories and the use of hydroxychloroquine. The difference was significant between normal and obese groups (Table 1). 
Table (1): Demographic features, laboratory investigations and medications received in systemic lupus erythematosus patients' groups based on body mass index

\begin{tabular}{|c|c|c|c|c|c|}
\hline \multirow[t]{2}{*}{ Variable } & $\begin{array}{c}\text { Normal group } \\
(30)\end{array}$ & $\begin{array}{l}\text { Overweight } \\
\text { group (36) }\end{array}$ & $\begin{array}{c}\text { Obese group } \\
(\mathbf{5 4})\end{array}$ & \multirow[t]{2}{*}{$\mathbf{P}$} & \multirow[t]{2}{*}{$\begin{array}{l}\text { LSD/Pairwise } \\
\text { comparison }\end{array}$} \\
\hline & $\begin{array}{c}\text { Median } \\
(\text { IQR })\end{array}$ & $\begin{array}{c}\text { Median } \\
(\text { IQR })\end{array}$ & $\begin{array}{c}\text { Median } \\
(\text { IQR }) \\
\end{array}$ & & \\
\hline $\begin{array}{l}\text { Age (years): } \\
\text { Mean } \pm \text { SD }\end{array}$ & $34.6 \pm 5.222$ & $34.67 \pm 4.367$ & $35.85 \pm 4.388$ & $0.550^{¥}$ & \\
\hline $\begin{array}{l}\text { Gender: } \\
\text { Female } \\
\text { Male }\end{array}$ & $\begin{array}{l}27(90 \%) \\
3(10 \%)\end{array}$ & $\begin{array}{c}33(91.7 \%) \\
3(8.3 \%)\end{array}$ & $\begin{array}{l}5(96.3 \%) \\
2(3.7 \%)\end{array}$ & $0.580^{\infty}$ & \\
\hline Disease Duration (year) & 5 & 5 & 3 & $0.346^{\#}$ & \\
\hline $\operatorname{ESR}(\mathrm{mm} / \mathrm{h})$ & 25 & 40 & 20 & $0.007 * \#$ & $\begin{array}{l}\text { P1 } 0.3 \\
\text { P2 } 0.008 * \\
\text { P3 } 0.895\end{array}$ \\
\hline CRP (mg/dL) & 8 & 9 & 7 & $0.066^{\#}$ & \\
\hline ANA titer & 0.0028 & 0.0017 & 0.0017 & $0.116^{\#}$ & \\
\hline $\begin{array}{l}\text { C3 }(\mathrm{mg} / \mathrm{dL}): \\
\text { Mean } \pm \text { SD }\end{array}$ & $97.33 \pm 14.849$ & $84.39 \pm \mathbf{1 3 . 6 2 6}$ & $104.07 \pm 13.365$ & $0.008^{*}$ & $\begin{array}{l}\text { P1 } 0.011^{*} \\
\text { P2 } 0.001^{*} \\
\text { P3 } 0.674\end{array}$ \\
\hline C4 (mg/dL) & 17 & 17 & 22 & $0.001 *$ & $\begin{array}{l}\text { P1 }>0.999 \\
\text { P2 } 0.011^{*} \\
\text { P3 } 0.005^{*}\end{array}$ \\
\hline $\begin{array}{c}\text { Serum Ca }(\mathrm{mg} / \mathrm{dL}) \\
\text { Mean } \pm \text { SD }\end{array}$ & $9.427 \pm 0.483$ & $9.383 \pm 0.375$ & $9.352 \pm 0.48$ & $0.767^{¥}$ & \\
\hline $\begin{array}{c}\text { Serum Phosphorus }(\mathrm{mg} / \mathrm{dL}) \\
\text { Mean } \pm \text { SD }\end{array}$ & $3.567 \pm 0.389$ & $3.483 \pm 0.407$ & $3.452 \pm 0.479$ & $0.513^{¥}$ & \\
\hline $\begin{array}{l}\text { Alkaline phosphatase (U/L) } \\
\text { Mean } \pm \text { SD }\end{array}$ & $96.87 \pm 13.249$ & $\begin{array}{l}91.11 \pm \\
17.511\end{array}$ & $82.89 \pm 12.839$ & $0.683^{¥}$ & \\
\hline $\begin{array}{c}\text { Vitamin D }(\mathrm{ng} / \mathrm{dL}) \\
\text { Mean } \pm \text { SD }\end{array}$ & $25.33 \pm 4.599$ & $24.67 \pm 3.163$ & $23.22 \pm 3.892$ & $0.387^{¥}$ & \\
\hline $\begin{array}{c}\text { Anti-ds-DNA (+ve) } \\
\text { N (\%) }\end{array}$ & $24(80 \%)$ & $28(77.8 \%)$ & $44(81.5 \%)$ & $0.823^{\infty}$ & \\
\hline $\begin{array}{c}\text { Steroid duration (month) } \\
\text { Cumulative steroid dose (gm) }\end{array}$ & $\begin{array}{l}60 \\
36 \\
\end{array}$ & $\begin{array}{r}60 \\
\quad 36.375 \\
\end{array}$ & $\begin{array}{c}42 \\
30.3 \\
\end{array}$ & $\begin{array}{l}0.373^{\#} \\
0.447^{\#}\end{array}$ & \\
\hline $\begin{array}{l}\text { Immunosuppressive use: } \\
\text { Yes n (\%) }\end{array}$ & $18(60 \%)$ & $32(88.9 \%)$ & $44(81.5 \%)$ & $0.014 * \infty$ & \\
\hline $\begin{array}{l}\text { Azathioprine Users n(\%) } \\
\text { Mycophenolate mofetil } \\
\text { Users n (\%) }\end{array}$ & $\begin{array}{c}16(46.7 \%) \\
2(6.7 \%) \\
\end{array}$ & $\begin{array}{l}30(83.3 \%) \\
2(5.6 \%) \\
\end{array}$ & $\begin{array}{c}44(77.8 \%) \\
0(0 \%) \\
\end{array}$ & $0.044 * \infty$ & $\begin{array}{ll}\text { P1 } & 0.612 \\
\text { P2 } & 0.174 \\
\text { P3 } & 0.081 \\
\end{array}$ \\
\hline $\begin{array}{l}\text { Hydroxychloroquine } \\
\text { Users n (\%) }\end{array}$ & $30(100 \%)$ & $32(88.9 \%)$ & $46(85.2 \%)$ & $0.022 * \infty$ & $\begin{array}{l}\text { P1 } 0.12 \\
\text { P2 } 0.756 \\
\text { P3 } 0.046^{*} \\
\end{array}$ \\
\hline
\end{tabular}

${ }^{\#}$ Kruskal - Wallis test, ${ }^{\infty} \mathrm{Chi}$-square test, ${ }^{*} \mathrm{~F}$ One way ANOVA test, ${ }^{*} \mathrm{p}<0.05$ is statistically significant

$\mathrm{P}_{1}$ Difference between normal and overweight groups $\mathrm{P}_{2}$ Difference between overweight and obese groups $\mathrm{P}_{3}$ Difference between normal and obese groups

BMI: Body mass index, ESR:erythrocyte sedimentation rate, CRP: C-reactive protein, ANA:antinuclear antibodies, C3:complement 3, C4: complement 4, Ca: Calcium Anti-ds-DNA: anti-double stranded- DNA

A highly significant increase in SLEDAI score and SLEDAI score grades was found in overweight and obese groups compared to the normal weight group. Severe activity was present in $44.4 \%$ of obese patients versus $5.6 \%$ of overweight ones. A significant increase in the prevalence of osteoporosis at T-score in obese groups; compared to the normal weight group (table 2). 
Table (2): Disease activity and bone mineral density in systemic lupus erythematosus patients' groups based on body mass index

\begin{tabular}{|c|c|c|c|c|c|}
\hline \multirow[t]{2}{*}{ Variable } & \begin{tabular}{|c} 
Normal group \\
$(30)$
\end{tabular} & \begin{tabular}{|c|}
$\begin{array}{c}\text { Overweight } \\
\text { group } \\
(36)\end{array}$ \\
\end{tabular} & $\begin{array}{c}\text { Obese } \\
\text { group } \\
(54)\end{array}$ & \multirow[t]{2}{*}{$\mathbf{P}$} & \multirow[t]{2}{*}{$\begin{array}{c}\text { Pairwise } \\
\text { comparison }\end{array}$} \\
\hline & Median (IQR) & Median (IQR) & Median (IQR) & & \\
\hline SLEDAI Score & 2 & 4 & 2 & $0.001^{\# *}$ & $\begin{array}{c}\text { P1 } 0.074 \\
\text { P2 }<0.001 * \\
\text { P3 } 0.641\end{array}$ \\
\hline \multicolumn{4}{|l|}{ SLEDAI severity } & \multirow{5}{*}{$0.002 * \infty$} & \multirow{5}{*}{$\begin{array}{c}\text { P1 } 0.08 \\
\text { P2 } 0.001 * \\
\text { P3 } 0.125\end{array}$} \\
\hline $\begin{array}{c}\text { Severe activity } \\
\mathrm{N}(\%)\end{array}$ & $6(20 \%)$ & $2(5.6 \%)$ & $24(44.4 \%)$ & & \\
\hline $\begin{array}{c}\text { Moderate activity } \\
\mathrm{N}(\%)\end{array}$ & $18(60 \%)$ & $20(55.6 \%)$ & $20(37 \%)$ & & \\
\hline $\begin{array}{c}\text { Mild activity } \\
\mathrm{N}(\%)\end{array}$ & $4(13.3 \%)$ & $12(33.3 \%)$ & $8(14.8 \%)$ & & \\
\hline No activity $\mathrm{N}(\%)$ & $2(6.7 \%)$ & $2(5.6 \%)$ & $2(3.7 \%)$ & & \\
\hline \multicolumn{4}{|c|}{ Osteoporosis rate (T-score) } & \multirow{4}{*}{$0.033^{* \infty}$} & \multirow[t]{2}{*}{ P1 0.177} \\
\hline Normal N $(\%)$ & $19(63.3 \%)$ & $\begin{array}{c}14 \\
(38.9 \%)\end{array}$ & $\begin{array}{c}16 \\
(29.6 \%)\end{array}$ & & \\
\hline $\begin{array}{l}\text { Osteopenia } \\
\mathrm{N}(\%)\end{array}$ & $5(16.7 \%)$ & $14(38.9 \%)$ & $19(35.2 \%)$ & & P2 0.481 \\
\hline $\begin{array}{c}\text { Osteoporosis } \\
\mathrm{N}(\%)\end{array}$ & $6(20 \%)$ & $8(22.2 \%)$ & $19(35.2 \%)$ & & P3 0.011* \\
\hline
\end{tabular}

SLEDAI: Systemic Lupus Erythematosus Disease Activity Index, ${ }^{\#}$ Kruskal - Wallis test, ${ }^{\infty} \mathrm{Chi}$-square test $* \mathrm{p}<0.05$. SLEDAI: Systemic Lupus Erythematosus Disease Activity Index, ${ }^{\#}$ Kruskal - Wallis test, ${ }^{\infty}$ Chi-square test $* \mathrm{p}<0.05$ is statistically significant.

$\mathrm{P}_{1}$ Difference between normal and overweight groups $\mathrm{P}_{2}$ Difference between overweight an obese groups $\mathrm{P}_{3}$ Difference between normal and obese groups

There was a statistically significant difference regarding vitamin D level between the obese group and the other 2 groups (table 3).

Table (3): Relation between vitamin D level and BMI of the studied patients

\begin{tabular}{|l|c|c|c|c|c|}
\hline & $\begin{array}{c}\text { Normal group } \\
\mathbf{N = 3 0}(\%)\end{array}$ & $\begin{array}{c}\text { Overweight } \\
\text { group } \\
\mathbf{N = 3 6}(\%)\end{array}$ & $\begin{array}{c}\text { Obese group } \\
\mathbf{N = 5 4}(\%)\end{array}$ & P & $\begin{array}{c}\text { Pairwise } \\
\text { comparison }\end{array}$ \\
\hline Deficiency & $0(0)$ & $0(0)$ & $0(0)$ & $0.015^{*}$ & P2 $0.035^{*}$ \\
Insufficiency & $18(60)$ & $23(63.9)$ & $45(83.3)$ & P3 $0.017^{*}$ \\
Sufficiency & $12(40)$ & $13(36.1)$ & $9(16.7)$ & & \\
\hline
\end{tabular}

$* \mathrm{p}<0.05$ is statistically significant

In addition, age, SLEDAI score, serum C3, and C4 were found to have a highly significant positive correlation with BMI (Table 4). 
Table (4): Correlation analysis for baseline clinical, laboratory, treatment and BMD data associated with BMI

\begin{tabular}{|l|l|c|c|}
\hline \multicolumn{2}{|c|}{ Associated Factor } & \multicolumn{2}{c|}{ BMI } \\
\cline { 2 - 4 } & Age (years) & 0.211 & P \\
\hline \multirow{5}{*}{ Clinical data } & SLEDAI score & 0.196 & $\mathbf{0 . 0 2 1}$ \\
& Duration (year) & -0.081 & 0.378 \\
\cline { 2 - 4 } & ESR (mm/h) & -0.087 & 0.342 \\
& CRP (mg/dL) & -0.129 & 0.162 \\
& ANA titer & -0.063 & 0.501 \\
& C3 (mg/dL) & 0.182 & $\mathbf{0 . 0 4 7}$ \\
& C4 (mg/dL) & 0.285 & $\mathbf{0 . 0 0 2}$ \\
& Ca (mg/dL) & -0.035 & 0.704 \\
& Phosphorus (mg/dL) & -0.106 & 0.249 \\
& Alkaline phosphatase (U/L) & -0.141 & 0.123 \\
& Vitamin D (ng/dL) & -0.126 & 0.170 \\
\hline \multirow{5}{*}{ Treatment data } & -0.074 & 0.419 \\
& Steroid duration (month) & -0.105 & 0.253 \\
\cline { 2 - 4 } & Cumulative steroid dose (gm) & 0.171 & 0.062 \\
\cline { 2 - 4 } & T-score (Neck Femur) & 0.051 & 0.581 \\
\hline
\end{tabular}

$\boldsymbol{r}$ Spearman rank correlation coefficient SLEDAI: Systemic Lupus Erythematosus Disease Activity Index, , ESR :erythrocyte sedimentation rate, CRP: c-reactive protein, ANA: antinuclear antibodies, C3:complement 3, C4: complement 4, Ca: Calcium, $* \mathrm{p}<0.05$ is statistically significant

There was a statistically significant positive correlation between SLEDAI score and BMI. On the other hand, there was a significant negative correlation between SLEDAI score and all of C3, alkaline phosphatase, and 25(OH) D. SLEDAI score was significantly negatively correlated with T score of both femur neck and lumbar spine (Table 5).

Table (5): Correlation analysis for baseline clinical, laboratory, treatment and BMD data associated with SLEDAI

\begin{tabular}{|l|l|c|c|}
\hline \multicolumn{2}{|l}{ Associated Factor } & \multicolumn{2}{l|}{ EDAI } \\
\cline { 3 - 4 } & Age (years) & -0.058 & P \\
\hline \multirow{5}{*}{ Clinical data } & BMI (kg/m ${ }^{2}$ ) & 0.196 & 0.533 \\
& Duration (year) & 0.004 & $0.032^{*}$ \\
& ESR (mm/h) & 0.124 & 0.962 \\
\cline { 2 - 4 } & CRP (mg/dL) & 0.076 & 0.176 \\
& ANA titer & -0.063 & 0.409 \\
& C3 (mg/dL) & -0.239 & 0.501 \\
& C4 (mg/dL) & -0.144 & $0.008^{*}$ \\
& P/C ratio & 0.076 & 0.117 \\
& Ca (mg/dL) & 0.045 & 0.407 \\
& Phosphorus (mg/dL) & 0.132 & 0.623 \\
& Alkaline phosphatase (U/L) & -0.181 & 0.151 \\
& Vitamin D (ng/dL) & -0.307 & $0.048^{*}$ \\
& & -0.021 & $0.001^{* *}$ \\
\hline \multirow{5}{*}{ Treatment data } & Steroid duration (month) & 0.003 & 0.82 \\
& Cumulative steroid dose (gm) & -0.262 & 0.978 \\
\cline { 2 - 4 } & T-score (Neck Femur) & -0.215 & $0.004^{*}$ \\
& T-score (Lumbar Spine) & & $0.018^{*}$ \\
& & & \\
\hline
\end{tabular}

r Spearman rank correlation coefficient SLEDAI: Systemic Lupus Erythematosus Disease Activity Index,

ESR :erythrocyte sedimentation rate, CRP: c-reactive protein, ANA: antinuclear antibodies, C3:complement 3, C4: complement 4 , Ca: Calcium, ${ }^{*} \mathrm{p}<0.05$ is statistically significant. 


\section{DISCUSSION}

Obesity has been described as a state of chronic, low-grade inflammation that is mediated by adipocytes producing cytokines, including TNF-alpha, IL-6, IL-8, and monocyte chemoattractant protein -1(MCP-1). Production of such cytokines is the trigger for subsequent activation of the inflammatory cascade and autoimmunity ${ }^{(17)}$.

In this study, $30 \%$ were overweight and $45 \%$ were obese which is consistent with that in previous studies. One study reported a 39\% prevalence of obesity among a cohort of women with lupus ${ }^{(18)}$ and the study of Katz et al. ${ }^{(19)}$ showed a prevalence of $29-50 \%$.

In the present study SLEDAI score was positively correlated with BMI. This also was reported by Patterson $\boldsymbol{e t} \boldsymbol{a l} .{ }^{(9)}$ who found that obesity was independently linked to worse patient-reported outcomes, including disease activity and symptoms of depression, pain, and fatigue In addition a high BMI in SLE patients was associated with more cognitive and renal affection ${ }^{(20)}$. Similarly, Teh et al. ${ }^{(21)}$ revealed that an increased BMI was complicated by worsening of disease activity as evaluated by SLEDAI score. So increase BMI in SLE patients could worsen the chronic inflammatory status, increasing the oxidative stress and increase the secretion of pro-inflammatory cytokines ${ }^{(\mathbf{1})}$.

Our study demonstrated that $25(\mathrm{OH})$ D levels were lower in obese and overweight in comparison to normal-weight SLE patients. Similarly, previous studies demonstrated an increased prevalence of vitamin D deficiency among SLE patients ${ }^{(22)}$.

Vitamin D deficiency is highly predominant in SLE patients as patients with SLE usually avoid the sun due to photosensitive rashes and the potential for disease flare ${ }^{(23)}$. Also, lupus nephritis is associated with a decreased 1-alpha-hydroxylase activity on $25(\mathrm{OH}) \mathrm{D}$, and a subsequent decrease in $1,25(\mathrm{OH}) 2 \mathrm{D}$ production and presence of vitamin D autoantibodies leading to its clearance $^{(24)}$.

Moreover, obesity is considered a risk factor for vitamin $\mathrm{D}$ deficiency as adipose tissue acts as the sinkhole for vitamin $\mathrm{D}^{(25)}$. Also, SLE patients with high BMI usually have a high body fat content which acts as a reservoir for lipid-soluble vitamin $\mathrm{D}$. At the same time, the release of vitamin D from fat is extremely slow and is proportional to vitamin $\mathrm{D}$ concentration in the adipose tissue to protect the body from toxic effects of active forms of vitamin D. Thus, excess body fat results in increased sequestration and low availability of vitamin $\mathrm{D}$, leading to low serum $25(\mathrm{OH})$ D levels ${ }^{(26)}$.

Indeed, it was found in previous studies that serum level of $25(\mathrm{OH}) \mathrm{D}$ is inversely associated with BMI, fat mass, and waist circumference ${ }^{(27-28)}$. This inverse correlation is also detected in the present study but it doesn't reach a significant level.

We found a negative correlation between SLEDAI score and 25(OH) D levels. Similarly, vitamin D deficiency among SLE patients was demonstrated and its connection to complications of the disease and disease severity was shown ${ }^{(29)}$. This could be attributed to increased levels of memory B lymphocytes, which may increase SLE disease activity ${ }^{(30)}$.

Vitamin $\mathrm{D}$ has a protective role through inhibition of differentiation of T helper 1- lymphocytes, $\mathrm{T}$ helper 17 lymphocytes, stimulation of $\mathrm{T}$ regulatory cells, inhibition of $\mathrm{B}$ cell proliferation, and decrease the production of autoantibodies ${ }^{(31)}$.

The prevalence of osteoporosis at T-score was higher in our overweight and obese groups of SLE patients compared to the normal-weight group. Similarly, studies revealed a high prevalence of osteoporosis in SLE patients ${ }^{(32-33)}$.

BMD usually decreases among SLE patients. This could be attributed to multifactor as elevated inflammatory cytokines, hormonal imbalance, renal impairment, metabolic, and medications as a corticosteroid $^{(34-35)}$

In this study, BMI was not correlated with BMD but the SLEDAI score was negatively correlated with 25(OH) D levels and BMD (T-score of neck Femur and T-score of the lumbar spine). Regarding our patients' treatment, a significant increase in azathioprine was found in overweight and obese groups as compared to the normal-weight group. This could be explained by the fact that obese SLE patients have the more active disease which demands the use of more immunosuppressive drugs like corticosteroids and AZA which could accelerate $25(\mathrm{OH}) \mathrm{D}$ metabolism and reduce vitamin $\mathrm{D}$ and $\mathrm{BMD}^{(27)}$.

In conclusion, we observed that increased BMI is common in SLE patients and is independently associated with higher disease activity, higher osteoporotic rates, and lower serum $25(\mathrm{OH})$ vitamin D levels.

These findings highlight the need for weight control and lifestyle interventions targeting lupus patients with overweight as obesity may represent a modifiable target for improving outcomes among obese SLE patients. Furthermore, routine assessment of vitamin D levels and BMD in SLE especially those presented with increased BMI is also highly recommended.

Finally, the cross-sectional design of our study limits us by simply showing an association between obesity and SLEDAI, serum $25(\mathrm{OH})$ vitamin D level, and BMI but not causality. Prospective studies are needed for further evaluation. long prospective studies on the effect of bodyweight reduction on SLE activity and vitamin D level .

Declaration of interests: The authors declared no conflicts of interest concerning the authorship and/or publication of this article.

\section{Support :}

The research was not funded. Costs were the responsibility of the authors and the instruments used in the study belong to the Faculty of Medicine, a part of Ain Shams University, which is a public governmental organization. The authors indicate no relationships/conditions/ circumstances that present a potential financial conflict of interest. No other financial disclosures. 
Author contributions: All authors were involved in drafting the article or revising it critically for important intellectual content, and all authors approved the final version to be published.

\section{REFERENCES}

1. Versini M, Jeandel P, Rosenthal E et al. (2014): Obesity in autoimmune diseases: Not a passive bystander. Autoimmun Rev., 13(9): 981-1000.

2. Katz P, Gregorich S, Yazdany J et al. (2010): Obesity and its measurement in a community-based sample of women with systemic lupus erythematosus. Arthritis Care Res (Hoboken), 63 (2):261-8.

3. Fischer K, Przepiera-Bedzak H, Sawicki M et al. (2017): Serum interleukin-23 in Polish patients with systemic lupus erythematosus: Association with lupus nephritis, obesity, and peripheral vascular disease. Mediat Inflamm., 17: 1-9.

4. Sinicato N, Postal M, Peres F et al. (2014): Obesity and Cytokines in Childhood-Onset Systemic Lupus Erythematosus. J Immunol Res., 3:1-6.

5. Amarilyo G, Iikuni N, Shi F et al. (2013): Leptin promotes lupus T-cell autoimmunity. Clin Immunol., 149 (3):530533

6. Fujita Y, Fujii T, Mimori T et al. (2014): Deficient leptin signaling ameliorates systemic lupus erythematosus lesions in MRL/Mp-Fas lprmice.J Immunol., 192(3):979-98.

7. Yu Y, Liu Y, Shi F et al. (2013): Cutting edge: leptininduced ROR $\gamma$ t expression in CD4+ T cells promotes Th17 responses in systemic lupus erythematosus. J Immunol., 190: 3054-3058.

8. Liu Y, Yu Y, Matarese G et al. (2012): Cutting edge: fasting induced hypoleptinemia expands functional regulatory $\mathrm{T}$ cells in systemic lupus erythematosus. $\mathrm{J}$ Immunol., 188 (5):2070-2073.

9. Patterson S, Schmajuk G, Jafri K et al. (2019): Obesity is independently associated with worse patient- reported outcomes in women with systemic lupus erythematosus. Arthritis Care \& Research, 71(1):126-133.

10.Deluca H, Cantorna $M$ (2001): Vitamin D: Its role and uses in immunology. FASEB J., 15: 2579-85

11. Fouad H, Yahia S, Elsaid A et al. (2019): Oxidative stress and vitamin D receptor BsmI gene polymorphism in Egyptian children with systemic lupus erythematosus: a single center study. Lupus, 28(6):771-777.

12. World Health Organization (2004): The international classification of adult underweight, overweight and obesity according to BMI. Geneve: World Health Organization. http://www.assessmentpsychology.com/icbmi.htm

13.Petri M, Orbai A, Alarcón G et al. (2012): Derivation and validation of the Systemic Lupus International Collaborating Clinics classification criteria for systemic lupus erythematosus. Arthritis \& Rheumatism, 64(8):26772686.

14. Bombardier C, Gladman D, Urowitz M et al. (1922): Derivation of the SLEDAI. A disease activity index for lupus patients. Arthritis \& Rheumatism, 35: 630-640.

15. Cook R, Gladman D, Pericak D et al. (2000): Prediction of short term mortality in systemic lupus erythematosus with time dependent measures of disease activity. Journal of Rheumatology, 27(8): 1892-1895.

16. Blake G, Fogelman I (2007): The role of DXA bone density scans in the diagnosis and treatment of osteoporosis. Postgraduate Medical Journal, 83(982):509-517.
17.Gregor M, Hotamisligil G (2011): Inflammatory mechanisms in obesity. Annu Rev Immunol., 29: 415-445.

18. Petri M (2000): Detection of coronary artery disease and the role of traditional risk factors in the Hopkins Lupus Cohort. Lupus, 9(3):170-5.

19. Katz P, Yazdany J, Julian L et al. (2011): Impact of obesity on functioning among women with systemic lupus erythematosus. Arthritis Care \& Research, 63(10): 13571364.

20.Versini M, Tiosano S, Comaneshter D et al. (2017): Smoking and obesity in systemic lupus erythematosus: A cross-sectional study. Eur J Clin Investig., 47: 422-427.

21. Teh P, Zakhary B, Sandhu V (2019): The impact of obesity on SLE disease activity: Findings from the Southern California Lupus Registry (SCOLR). Clin Rheumatol., 38: 597-600.

22. Attar S, Siddiqui A (2013): Vitamin D deficiency in patients with systemic lupus erythematosus. Oman Med J., 28:42-7.

23. Kamen D, Aranow C (2008): The link between vitamin D deficiency and systemic lupus erythematosus. Curr Rheumatol Rep., 10: 273-280.

24. Le Goaziou M, Contardo G, Dupraz C et al. (2011): Risk factors for vitamin D deficiency in women aged 20-50 years consulting in general practice: a cross-sectional study. Eur J Gen Pract., 17(3):146-152.

25. Looker A (2007): Do body fat and exercise modulate vitamin D status? Nutr Rev., 65(2):124-S126.

26. Bischof M, Heinze G, Vierhapper H (2006): Vitamin D status and its relation to age and body mass index. Horm Res., 66: 211-215.

27.Jorde R, Sneve M, Emaus N et al. (2010): Cross-sectional and longitudinal relation between serum 25 -hydroxyvitamin D and body mass index: the tromso study. Eur J Nutr., 49: 401-407.

28. Rajakumar K, de lasHeras J, Chen $\mathbf{T}$ et al. (2011): Vitamin D status, adiposity, and lipids in black American and Caucasian children. J Clin Endocrinol Metab., 96: 1560-1567.

29. Mok C, Birmingham D, Ho L et al. (2012): Vitamin D deficiency as marker for disease activity and damage in systemic lupus erythematosus: a comparison with antidsDNA and anti-C1q. Lupus, 21: 36-42.

30. Yamamoto E, Nguyen J, Liu J et al. (2020): Low levels of vitamin D promote memory B cells in lupus. Nutrients, 12(2):291-93.

31.Penna G, Adorini L (2000): $1 \alpha, 25$-dihydroxyvitamin D3 inhibits differentiation, maturation, activation, and survival of dendritic cells leading to impaired alloreactive $\mathrm{T}$ cell activation. J Immunol., 164:2405-2411.

32. El-Hady H, Kora M, Soliman S et al. (2014): Study of bone mineral density in patients with systemic lupus erythematosus. Menouf Med J., 27:556-59.

33. Almehed K, Forsblad d'Elia H, Kvist G et al. (2007): Prevalence and risk factors of osteoporosis in female SLE patients. Rheumatology, 46(7):1185-90.

34. Lai E, Huang W, Chen $H$ et al. (2020): Degraded microarchitecture by low trabecular bone score is associated with prevalent vertebral fractures in patients with systemic lupus erythematosus. Arch Osteoporos, 15:54-58.

35. De Martinis M, Sirufo M, Ginaldi $L$ (2020): Osteoporosis: current and emerging therapies targeted to immunological checkpoints. Curr Med Chem., 21(23): 8887. 